\title{
POLY(ACRYLAMIDE-co-STYRENE SODIUM SULFONATE) AND POLY(2-ACRYLAMIDE-2-METHYL-1- PROPANESULFONIC ACID-CO-ACRYLIC ACID) RESINS WITH REMOVAL PROPERTIES FOR Hg(II), Pb(II), Cd(II), and Zn(II)
}

\author{
DANIELA V. MORALES AND BERNABÉ L. RIVAS* \\ Polymer Department, Faculty of Chemistry, University of Concepción, Casilla 160-C, Concepción, Chile.
}

\begin{abstract}
The water-insoluble polymers poly(acrylamide-co-styrene sodium sulfonate) (P(AAm-co-ESS)) and poly(2-acrylamide-2-methyl-1-propanesulfonic acidco-acrylic acid) (P(APSA-co-AAc)) were synthesized by radical polymerization. Parameters including the water sorption capacity, effect of the pH and reaction time, maximum retention capacity of the metal ions, elution, regeneration, and selectivity were studied. The commercial resin Amberlite IRP-64 was used for comparative purposes. Laboratory tests showed that both of the resins had better capacities to remove $\mathrm{Pb}(\mathrm{II}), \mathrm{Cd}(\mathrm{II}), \mathrm{Zn}(\mathrm{II})$, and $\mathrm{Hg}(\mathrm{II})$ from an aqueous solution by the batch method. P(AAm-co-ESS) and P(APSA-co-AAc) resins remove the metal ions faster and had better regeneration than commercial Amberlite IRP-64 resin.
\end{abstract}

\section{INTRODUCTION}

The main industrial wastes discharged into water without previous treatment are salts of heavy metals, inorganic and organic substances (such as vegetable nutrients that favor the growth of aquatic plants), medicines, radioactive elements (from uranium mining and medical supplies), chemical pesticides, surfactants, detergents, and pathogens, among others.

Heavy metals are metallic elements with relatively high densities that are toxic at low concentrations. Heavy metals are classified into three main groups as toxic metals (such as $\mathrm{Hg}, \mathrm{Cr}, \mathrm{Pb}, \mathrm{Zn}, \mathrm{Cu}, \mathrm{Ni}, \mathrm{Cd}, \mathrm{As}, \mathrm{Co}, \mathrm{Sn}$, etc.) precious metals (such as $\mathrm{Pd}, \mathrm{Pt}, \mathrm{Ag}, \mathrm{Au}, \mathrm{Ru}$, etc.), and radionuclides (such as $\mathrm{U}, \mathrm{Th}, \mathrm{Ra}, \mathrm{Am}$, etc.). Contamination of wastewaters by toxic metal ions is a worldwide environmental problem. The main sources of pollution are mining and electroplating industries discharging a variety of toxic metals such as $\mathrm{Pb}$, $\mathrm{Cu}, \mathrm{Ni}, \mathrm{Zn}, \mathrm{As}$, and $\mathrm{Cd}$ ions into soils and water bodies. ${ }^{1}$

The presence of heavy metal ions such as cadmium, lead, chromium, copper, and zinc in water often indicates anthropogenic environmental pollution. These metals are of special concern because they are nondegradable and can be bioaccumulated. In industrial wastewater streams and urban runoff samples, copper and zinc are detected in more than $90 \%$ of cases, whereas the percentage of cadmium, lead, and chromium was smaller. ${ }^{2}$

Today, increasing amounts of mercury are discarded into the environment (air, soil, and water) due to its use in the pharmaceutical and paper industries, production of electric batteries, amalgam dental fillings, combustion of coal or oil, and electrolytic production of chlorine and electronic devices. Food, however, is a source of entry of mercury into the human population. Mercury accumulates in the food chain reaching man. The World Health Organization (WHO) recommends a maximum intake of 2-20 $\mu \mathrm{g}$ mercury/day per person. In addition, the content in fish used for food should not exceed $1 \mu \mathrm{g} / \mathrm{kg} .^{3}$

Lead is found mainly as galena, $\mathrm{PbS}$, and more rarely as $\mathrm{PbCO}_{3}, \mathrm{PbCrO}_{4}$, and $\mathrm{PbSO}_{4}$. Lead contamination is often derived from human activities including from waste material (plumbing and batteries), soldering and alloys, chemicals such as paint pigments, lead alkyls (tetraethyl lead), organic compounds of lead (tetraethyl and tetramethyl lead) that are used as anti-knock additives in gasoline and oils used as lubricants. This metal is highly toxic to humans. Lead is neurotoxic and carcinogenic as it causes kidney cancer at low concentrations. According to the WHO, the maximum allowed limit is $0.01 \mathrm{mg} / \mathrm{L} .{ }^{3,4}$

Zinc is a trace element found in food and water as salts or organic complexes. The principal compounds that can be found are $\mathrm{ZnS}, \mathrm{ZnCO}_{3}$, and $\mathrm{Zn}_{2} \mathrm{SiO}_{4} \cdot \mathrm{H}_{2} \mathrm{O}$. The diet is the main source of this metal. Zinc levels in the surface and ground water should not exceed $0.01 \mathrm{mg} / \mathrm{L}$ and $0.05 \mathrm{mg} / \mathrm{L}$, respectively. Drinking water containing levels above $3.0 \mathrm{mg} / \mathrm{L}$ of zinc is not acceptable for consumption. ${ }^{3}$

Cadmium is found in nature as $\mathrm{CdS}$ and $\mathrm{CdCO}_{3}$ and is mostly found in the company of similar zinc compounds. This metal is a common pollutant from the fertilizer industry, the manufacturing of zinc and alloys, electrowinning processes, the oil industry, electric batteries, and others. Food is the main daily source of cadmium exposure, and the recommended maximum daily intake is 10-35 $\mu \mathrm{g}$. Cadmium is cumulative (it is stored in the kidneys and liver) has a half-life of 10-35 years in humans, and affects the metabolism of proteins and carbohydrates. The critical concentration in kidneys is usually close to 200 $\mathrm{mg} / \mathrm{kg}{ }^{3}$

Today, numerous research studies have been performed to developed methods to remove heavy metals ions, especially from wastewaters produced by hydrometallurgy and related industries, in order to reuse the water. The principal techniques are chemical precipitation, coagulation, evaporation, adsorption, solvent extraction, ultrafiltration membranes, inverse osmosis, biological treatment, chemical and electrochemical techniques, and finally ion exchange, which uses ion exchange resins or chelating agents. ${ }^{4-25}$, Many researchers have studied metal ion recovery using chelating polymers or resins because the use presents suitable characteristics and several advantages over the other methods for cleaning water. Ion exchange resins are stable over a wide range of $\mathrm{pH}$ values (1-10) and operating temperatures. They are inexpensive, fast, reusable, and easy to operate in a continuous way to achieve clean water. ${ }^{14-17}$ In addition, polymer resins are capable of removing a large percentage of the contaminants in solution. With the ion exchange procedure a high efficiency and selectivity would be possible.

For practical uses, strong and selective binding of metal ion, rapid interaction between the active site and the metal ion, and recovery of the resin is necessary. Moreover, minimal loss of the metal ion retention capability after many cycles of applications is needed. ${ }^{19}$ In this context, we have reported in the last few years the synthesis of numerous adsorbents bearing amide, amine, ammonium, carboxylic and sulfonic acid groups by radical polymerization our results shows very good removal properties for the metal ions $\mathrm{Hg}(\mathrm{II}), \mathrm{Cd}(\mathrm{II})$, $\mathrm{Pb}(\mathrm{II})$, and $\mathrm{Zn}(\mathrm{II}){ }^{14}$

The aim of this work is to obtain a polymer material containing different moieties at the backbone in order to increase the efficiency and selectivity to remove hazardous pollutants

\section{EXPERIMENTAL PART}

\section{Materials}

The reagents used to synthesize the ion exchange resins, poly(acrylamideco-styrene sodium sulfonate) (P(AAm-co-ESS)) and poly(2-acrylamide-2methyl-1-propanesulfonic acid-co-acrylic acid) (P(APSA-co-AAc)) were acrylamide, the hydrated sodium salt of 4-styrenesulfonate acid, acrylic acid (99\%), 2-acrylamide-2-methyl-1-propanesulfonic acid, N,N'-methylene-bisacrylamide $(99 \%)$, and ammonium persulfate $(98 \%)$. All these reagents and the commercial resin Amberlite IRP-64 were purchased from Sigma-Aldrich. The reagents for studying the removal properties were cadmium nitrate tetrahydrate ( $99 \%$ p.a.), zinc nitrate hexahydrate ( $98 \%$ p.a.), lead (II) nitrate ( $99 \%$ p.a.), mercury nitrate monohydrate ( $99 \%$ p.a.), hydrochloric acid (37\%), nitric acid $(65 \%)$, and perchloric acid $(60 \%$ p.a. $)$. All the salts and acid solutions were purchased from Merck.

Instrumentation

The laboratory equipment used in the experimental stage of this research included: (a) a Shimadzu analytical balance; (b) a Julabo thermostatic bath; (c) a Memmert heater; (d) a Unicam Solaar 5M atomic absorption spectrometer; 
(e) an Ezodo Pl-600 digital pH meter; (f) a Jeol JSM-6380 LV scanning electron microscope; (g) a Magna Nicolet, TF-IR spectrometer 550; (h) a set of stainless steel sieves of 100, 180, and $250 \mu \mathrm{m}$; and (i) an IKA A11 basic grinder.

Synthesis of P(AAm-co-ESS) and P(APSA-co-AAc)

The P(AAm-co-ESS) and P(APSA-co-AAc) resins were synthesized at laboratory scale by radical polymerization using acrylamide and the hydrated sodium salt of 4-styrenesulfonate acid for P(AAm-co-ESS) monomer, and 2-acrylamide-2-methyl-1-propanesulfonic acid and acrylic acid for P(APSAco-AAc) monomer. $\mathrm{N}, \mathrm{N}^{\prime}$-methylene-bis-acrylamide $(4 \mathrm{~mol} \%)$ was used as crosslinking reagent and $1 \mathrm{~mol} \%$ of ammonium persulfate was used as initiator. All of the reagents were introduced into a polymerization flask with $10 \mathrm{~mL}$ of water and were kept under a $\mathrm{N}_{2}$ atmosphere for $24 \mathrm{~h}$ at $70^{\circ} \mathrm{C}$. The resins were then filtered, washed with distilled water, and finally dried in an oven at $40^{\circ} \mathrm{C}$ until constant weights were obtained. The synthetic routes of P(AAm-co-ESS) and P(APSA-co-AAc) are shown in Figures 1 and 2, respectively. The structure of the commercial resin Amberlite IRP-64 is shown in Figure 3 for reference.

\section{Characterization}

The $\mathrm{P}(\mathrm{AAm}-\mathrm{co}$-ESS) and $\mathrm{P}(\mathrm{APSA}-\mathrm{co}-\mathrm{AAc})$ resins were characterized by FT-IR, DSC and TGA. The infrared spectroscopy was operated over the range of 400 to $4000 \mathrm{~cm}^{-1}$ to identify the typical absorption signals of the resin exchange groups. The diferential scanning calorimetry was performed at $10^{\circ} \mathrm{C} / \mathrm{min}$ and $170^{\circ} \mathrm{C}$ for $\mathrm{P}\left(\mathrm{AAm}-\mathrm{co}\right.$-ESS) and $270^{\circ} \mathrm{C}$ for P(APSA-co-AAc) to confirm if the resins are crystalline, semicrystalline, or amorphous. The thermogravimetric analysis, TGA, was carried out between 30 and $550^{\circ} \mathrm{C}$ at $10^{\circ} \mathrm{C} / \mathrm{min}$ for both resins.

\section{Degree of swelling}

For each resin, $100 \mathrm{mg}$ of dry resin and $80 \mathrm{~mL}$ of double distilled water were introduced and kept in a $100-\mathrm{mL}$ beaker over $24 \mathrm{~h}$ for the evaluation of the degree of resin swelling. Once the residence time was completed, the beaker content was filtered, and the wet resin was weighed to obtain the mass of water absorbed per gram of resin (see Eq. 1). The resins can be classified as (a) xerogel $\left(0 \mathrm{~g} \mathrm{H}_{2} \mathrm{O} / \mathrm{g}\right.$ resin), (b) hydrogel (0-100 $\mathrm{g} \mathrm{H}_{2} \mathrm{O} / \mathrm{g}$ resin), and (c) superabsorbent (higher than $100 \mathrm{~g} \mathrm{H}_{2} \mathrm{O} / \mathrm{g}$ resin).

\section{Metal ion adsorption}

A batch equilibrium procedure was applied to determine the metal ion binding ability of the synthesized resins. All the experiments were performed in a flask mounted on a shaker at $25^{\circ} \mathrm{C}$. The adsorption equilibrium experiments were carried out to study the effect of $\mathrm{pH}$, contact time, maximum retention capacity, elution, regeneration, and selectivity.

To study the effect of the $\mathrm{pH}$ on the removal of the metal ions, solutions were prepared at $\mathrm{pH}$ values of 1 and 2 for $\mathrm{Hg}(\mathrm{II}), \mathrm{pH}$ values of $1,2,3,5$, and 7 for $\mathrm{Cd}(\mathrm{II})$ and $\mathrm{Zn}$ (II); and $\mathrm{pH}$ values of 1-5 for $\mathrm{Pb}$ (II) using a molar ratio of 20:1 (resin: metal ion). The $\mathrm{pH}$ values were adjusted with $\mathrm{HNO}_{3}$ and $\mathrm{NaOH}$. After
$0.05 \mathrm{~g}$ of resin was introduced to $5 \mathrm{~mL}$ of a metal ion solution, each solution was stirred for $60 \mathrm{~min}$ at $140 \mathrm{rpm}$ and $25^{\circ} \mathrm{C}$.

The effect of the contact time on the metal ion retention was studied. Metal ion solutions that presented a higher retention percentage were used and were exposed to the resins for $15,30,60$, and 120 min while keeping the $\mathrm{pH}$, temperature and molar ratio constant. The metal ion solutions were exposed to $0.05 \mathrm{~g}$ of resin in a thermostatic bath with constant stirring at a rate of 140 rpm at $25^{\circ} \mathrm{C}$.

In the maximum retention capacity a metal ion solution with a concentration of approximately $1 \mathrm{~g} / \mathrm{L}$ was prepared. The optimum $\mathrm{pH}$ was adjusted for each particular metal ion. One half-gram of each resin was exposed to $10 \mathrm{~mL}$ of the metal ion solution for $60 \mathrm{~min}$ at $25^{\circ} \mathrm{C}$ with stirring at a rate of $140 \mathrm{rpm}$.

To determine the best eluent for regenerating the resin, three different acids were used: hydrochloric acid, nitric acid, and perchloric acid at concentrations of 1 and $4 \mathrm{~mol} / \mathrm{L}$. For this study, each resin was charged with metal ions at the maximum retention capacity level and was then exposed to $10 \mathrm{~mL}$ of acid for $60 \mathrm{~min}$ at $140 \mathrm{rpm}$ and $25^{\circ} \mathrm{C}$.

In the regeneration experiment of the resin, $10 \mathrm{~mL}$ of metal ion solution were exposed at the optimum $\mathrm{pH}$ for $60 \mathrm{~min}$ at $140 \mathrm{rpm}$ and $25^{\circ} \mathrm{C}$. The resins were further purged of the metal ions by stirring at the optimal acid concentration for $60 \mathrm{~min}$ at $140 \mathrm{rpm}$ and $25^{\circ} \mathrm{C}$, and then they were filtered and washed. This cycle of charging and discharging the resin was repeated three consecutive times.

For the removal selectivity study of the resins, ternary and quaternary mixtures of metal ions were investigated. It is the capacity of the resin to recover one specific metal ion from a mixture of metal ions solution. Solutions containing tertiary and quaternary mixtures with $\mathrm{Pb}(\mathrm{II}), \mathrm{Cd}(\mathrm{II})$, and $\mathrm{Zn}(\mathrm{II})$, and $\mathrm{Pb}(\mathrm{II}), \mathrm{Cd}(\mathrm{II}), \mathrm{Zn}(\mathrm{II})$, and $\mathrm{Hg}(\mathrm{II})$ metal ions, respectively, were prepared, maintaining a molar ratio of 20:1 at a pH value of 5 for the tertiary solution and a pH value of 2 for the quaternary solution. The resins were exposed to $5 \mathrm{~mL}$ of each metal ion solution at the specified $\mathrm{pH}$ for $60 \mathrm{~min}$ at $140 \mathrm{rpm}$ and $25^{\circ} \mathrm{C}$.

In all the experiments the solutions were filtered and washed for analyses by Atomic Absorption Spectroscopy (AAS).

\section{RESULTS AND DISCUSSION}

Water-insoluble resins containing sulfonic acid and amido groups for $\mathrm{P}(\mathrm{AAm}-\mathrm{co}-\mathrm{ESS})$, and sulfonic and carboxylic acids for P(APSA-co-AAc) were obtained by copolymerization of an equimolar ratio of the co-monomers acrylamide and the hydrated sodium salt of 4-styrenesulfonate acid for $\mathrm{P}(\mathrm{AAm}-\mathrm{co}$-ESS), and 2-acrylamide-2-methyl-1-propane sulfonic acid and acrylic acid for P(APSA-co-AAc) (see figs. 1 and 2). The yield for these resins was $100 \%$ for both. Figure 3 shows the commercial resin Amberlite IRP-64 content carboxylic acid group.

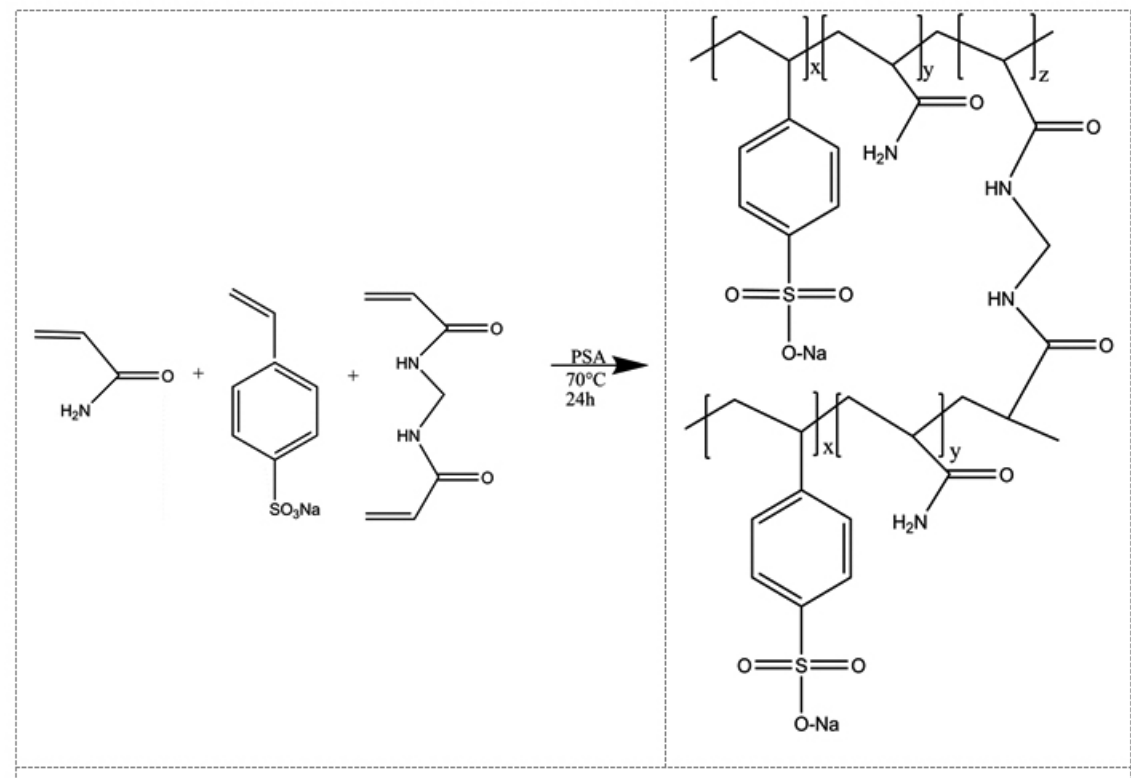

Fig. 1 Route of synthesis of P(AAm-co-ESS). 


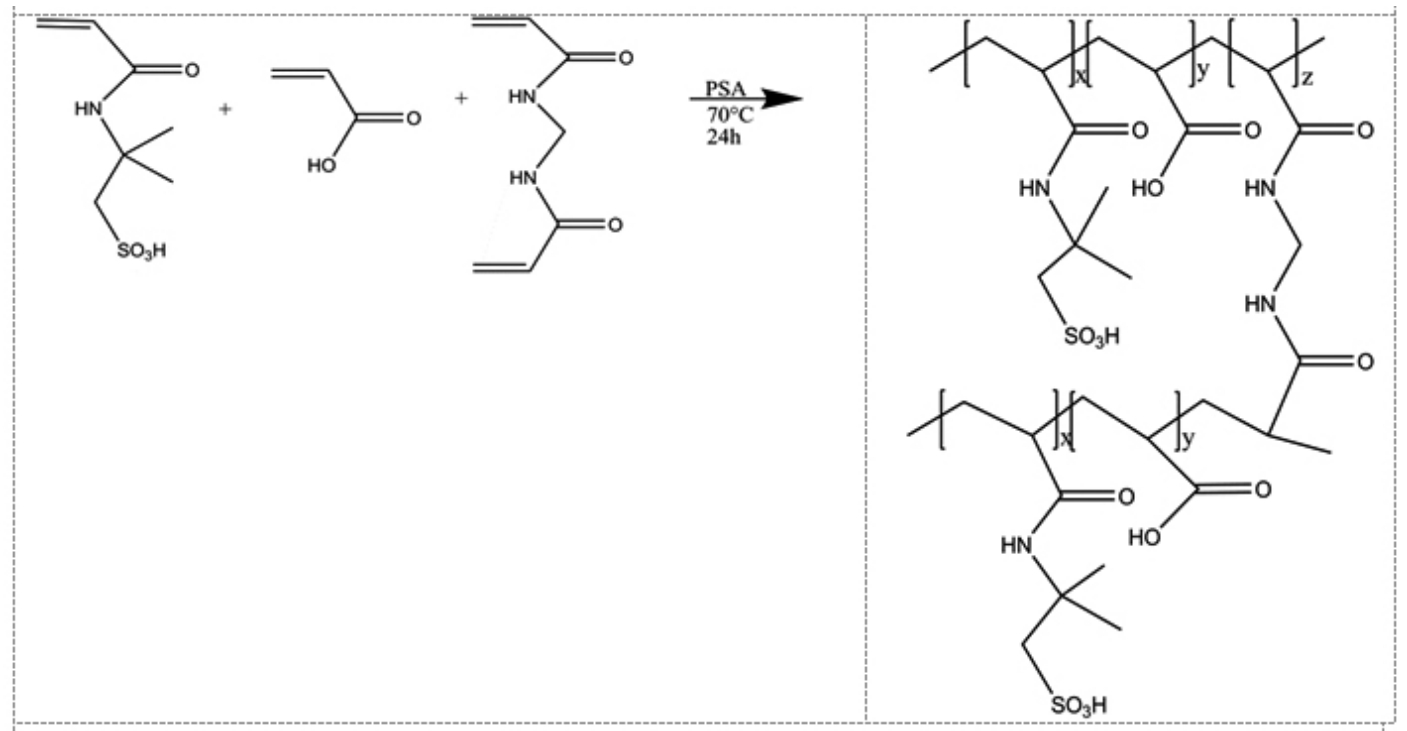

Fig. 2 Route of synthesis of P(APSA-co-AAc).

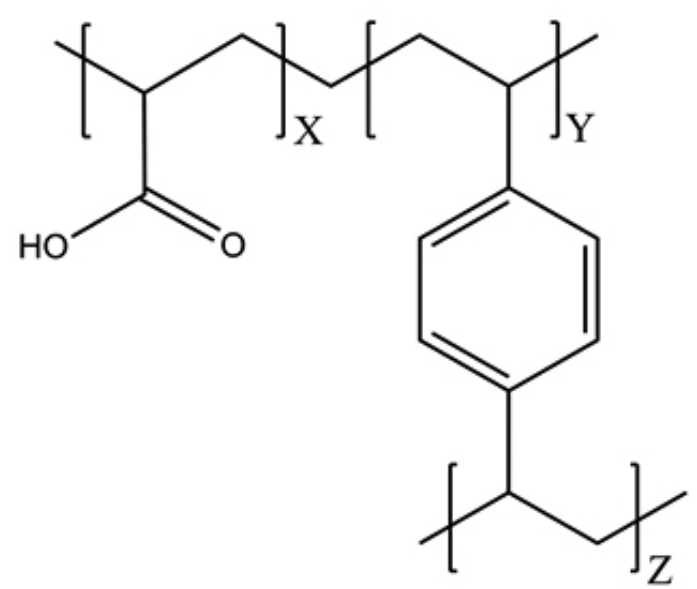

Fig. 3 Structure of commercial resin Amberlite IRP-64.

\section{Characterization}

Figures 4 and 5 show the corresponding FTIR spectra of the synthesized resin and the $\mathrm{Pb}$ charged resin for $\mathrm{P}(\mathrm{AAm}-\mathrm{co}$-ESS) and $\mathrm{P}(\mathrm{APSA}-\mathrm{co}-\mathrm{AAc})$, respectively, which corroborates their polymer structures. Table 1 summarizes the characteristic absorption signals observed in the spectra of each resin for the detailed cases. IR analysis shows the typical signals of the functional groups, including the $-\mathrm{OH}$ of the carboxylic acid and amide, the $-\mathrm{C}=\mathrm{O}$ of the carboxylic acid and amide, and the $-\mathrm{SO}_{3} \mathrm{H}$, for the synthesized $\mathrm{P}(\mathrm{AAm}-$ co-ESS) resin and the charged resin with $\mathrm{Pb}(\mathrm{II})$. In the presence of the metal ion, the intensity of the IR signals tended to increase for the wavelength range of the functional groups under analysis. The same trend was verified for the $\mathrm{P}(\mathrm{APSA}-\mathrm{co}-\mathrm{AAc})$ resin. There is no variation in the characteristic signals in the resin alone or in the presence of the $\mathrm{Pb}$ (II) solution, indicating there was no disappearance or formation of new functional groups, that is, no metal ion complexation is observed for the removal of ions.

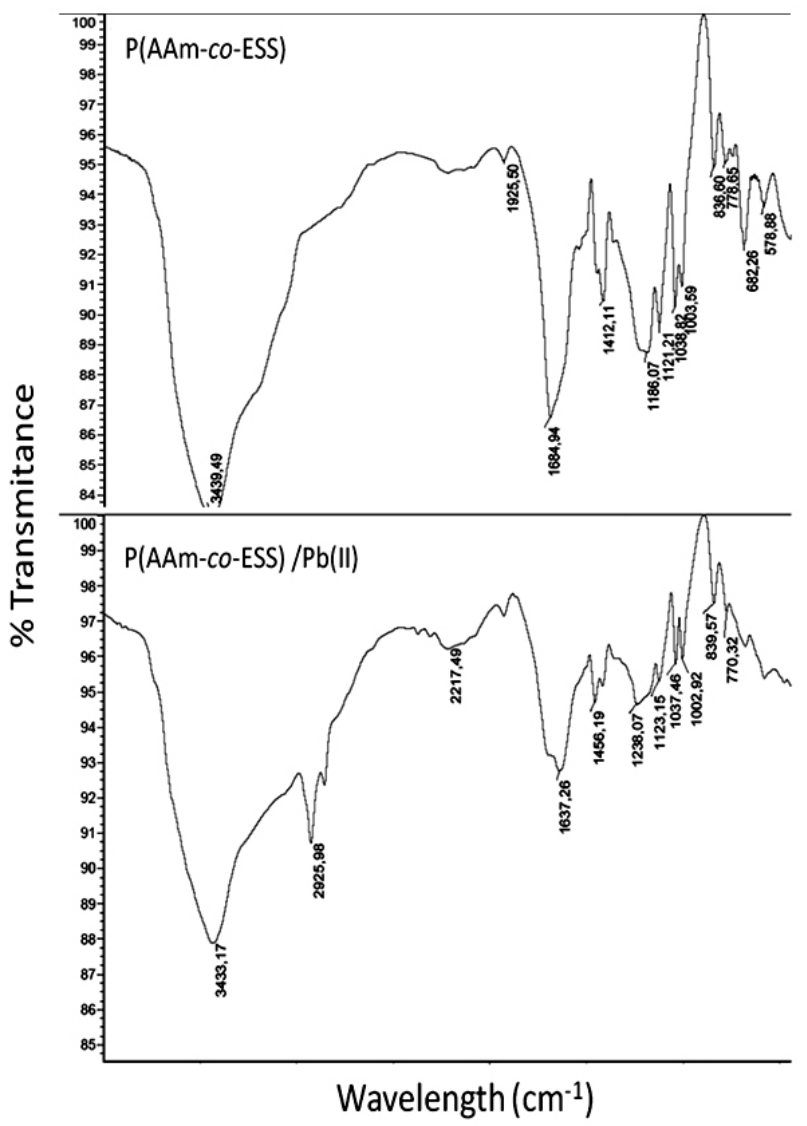

Fig. 4 Infrared spectroscopy of $\mathrm{P}(\mathrm{AAm}-\mathrm{Ao}$-ESS) with and without $\mathrm{Pb}(\mathrm{II})$. 


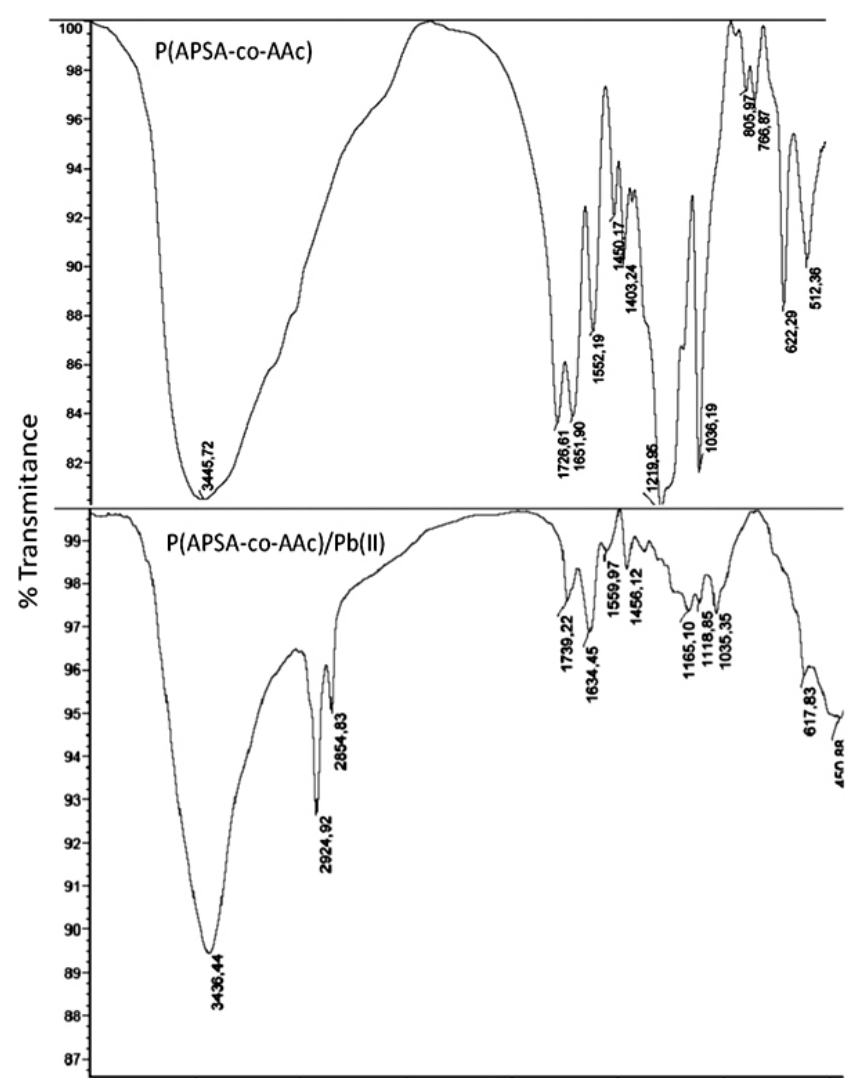

Wavelength $\left(\mathrm{cm}^{-1}\right)$

Fig. 5 Infrared spectroscopy of P(APSA-co-AAc) with and without Pb(II).

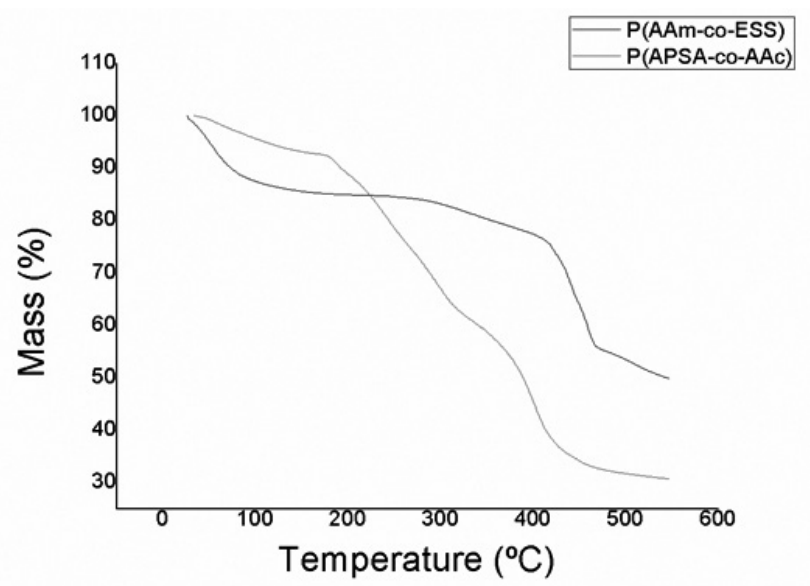

Fig. 6 Thermogravimetric profiles for $\mathrm{P}(\mathrm{AAm}-\mathrm{co}$-ESS) and P(APSA-coAAc) resins.

The thermogravimetric analysis determinates the decomposition temperature of the resins, this parameter allows to determinate de stability of the resins with the temperature. The differential scanning calorimetry (DSC) permits to determine thermal behavior related to physical and chemicals changes, when the temperature varies in the transition zone or reaction.

The TGA profile of $\mathrm{P}(\mathrm{AAm}-\mathrm{co}$-ESS) resin in the figure 6 shows a decomposition at $54.0^{\circ} \mathrm{C}$ attributed to water. The first decomposition occurs at $439.0^{\circ} \mathrm{C}$ which is attributed to the acrylamide moiety and the decomposition at $480.0^{\circ} \mathrm{C}$ due to the hydrated sodium salt of 4 -styrenesulfonate acid. With the last decomposition the mass decreases up to $45.07 \%$, the resin is decomposed in sulfur dioxide and ammonium.

The TGA profile for P(APSA-co-AAc) resin shows a decomposition at $58.3^{\circ} \mathrm{C}$ attributed to water, the first decomposition occurs at $188.5^{\circ} \mathrm{C}$ and continued with consecutive decompositions at $241.5^{\circ} \mathrm{C}, 301.0^{\circ} \mathrm{C}$, and $400.5^{\circ} \mathrm{C}$ attributed the carboxylic and sulfonic acid groups. With the last decomposition the mass deacreases in $26.85 \%$. The resin is decomposed in sulfur and cabon dioxide.

$\mathrm{P}(\mathrm{Aam}-\mathrm{co}$-ESS) resin is more stable than $\mathrm{P}(\mathrm{APSA}-\mathrm{co}-\mathrm{AAc})$ resin, probably for the stability given by the benzene group.

The DSC profile of the resins shown in figure 7 demonstrates that both resins have a small crystalline part, with a melting temperature of $133.3^{\circ} \mathrm{C}$ for $\mathrm{P}\left(\mathrm{AAm}-\mathrm{co}\right.$-ESS) resin, and $136.3^{\circ} \mathrm{C}$ for $\mathrm{P}(\mathrm{APSA}-\mathrm{co}-\mathrm{AAc})$ resin. This technique also gives the enthalpy values of $346.0 \mathrm{~J} / \mathrm{g}$ for $\mathrm{P}(\mathrm{AAm}-\mathrm{co}$-ESS) resin and $286.4 \mathrm{~J} / \mathrm{g}$ for P(APSA-co-AAc) resin, both are endothermic processes.

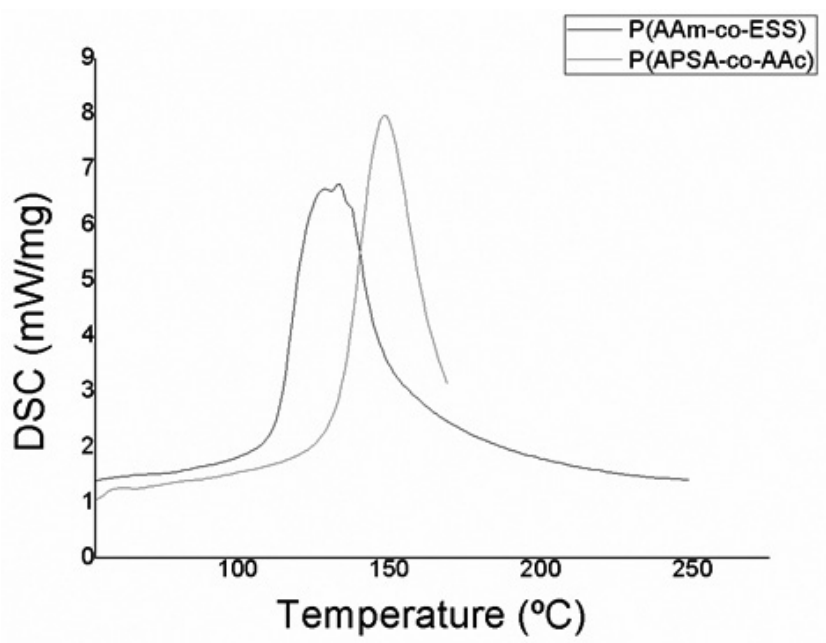

Fig. 7 Diferential scanning calorimetry of P(AAm-co-ESS) and P(APSAco-AAc) resins.

\section{Degree of swelling (DS)}

The ability to swell is one of the most important properties of ion exchange materials. Almost all ion exchange reactions involve the internal solution of the exchanger. Another important property is the nature of the ion exchange groups, and in this case, both resins contain hydrophilic carboxylic and sulfonic acid groups with high affinities for water.

To determine the DS, the following equation was used:

$$
\text { Degree of swelling }=\frac{\text { Wet mass of resin }}{\text { Dry mass of resin }}
$$

For this study, between 180 and $250 \mu \mathrm{m}$ of resin was used. The resins demonstrate high water absorption capacities; thus, the pores of the resins opened large enough to allow the diffusion of water inside of the resins. According to the results obtained in this study, the synthesized resins are hydrogel-type resins $\left(8.26 \mathrm{gH}_{2} \mathrm{O} / \mathrm{g}\right.$ resin for $\mathrm{P}(\mathrm{AAm}-\mathrm{co}$-ESS $)$ and $10.21 \mathrm{~g}$ $\mathrm{H}_{2} \mathrm{O} / \mathrm{g}$ resin $\mathrm{P}($ APSA-co-AAc) $)$.

\section{Effect of pH}

The $\mathrm{pH}$ studied depends on the metal ion solubility. The resins showed a dependence on $\mathrm{pH}$, as the metal ion form and the active groups change with the $\mathrm{pH}$. At $\mathrm{pH}$ below $\mathrm{pKa}$, the resin will be protonated, and at $\mathrm{pH}$ over $\mathrm{pKa}$ will be deprotonated. The metal ions studied are found as cationic form at the $\mathrm{pH}$ of the experiment. A coordination/chelation mechanism at low $\mathrm{pH}$ and ion exchange mechanism at high $\mathrm{pH}$ are suggested. The most commom cation exchangers are strongly acid resins with sulphonic acid groups $\left(-\mathrm{SO}_{3} \mathrm{H}\right)$ with a $\mathrm{pk} \leq 1$, and weakly acid resins with carboxylic acid groups $(-\mathrm{COOH})$ with a $\mathrm{pK} 3.5-8 .{ }^{18}$ 


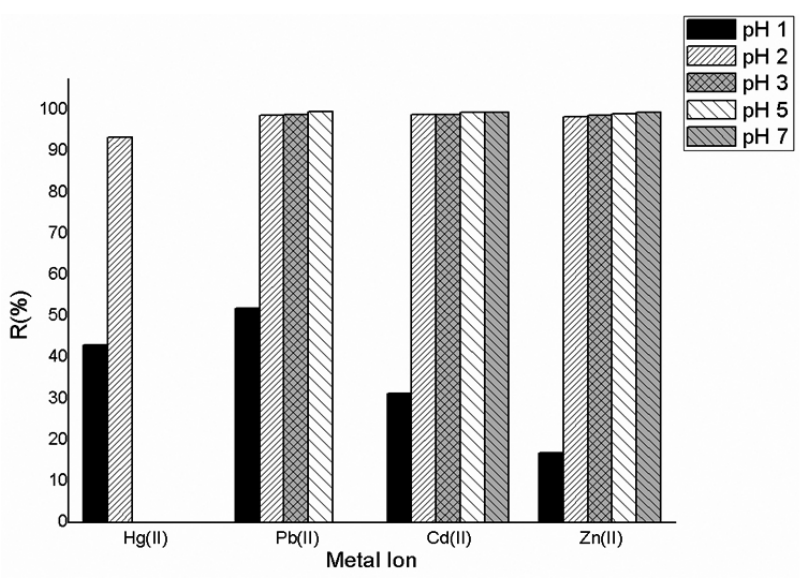

Fig. 8 Retention of metal ions at different $\mathrm{pHs}$ for $\mathrm{P}(\mathrm{AAm}-\mathrm{co}$-ESS).

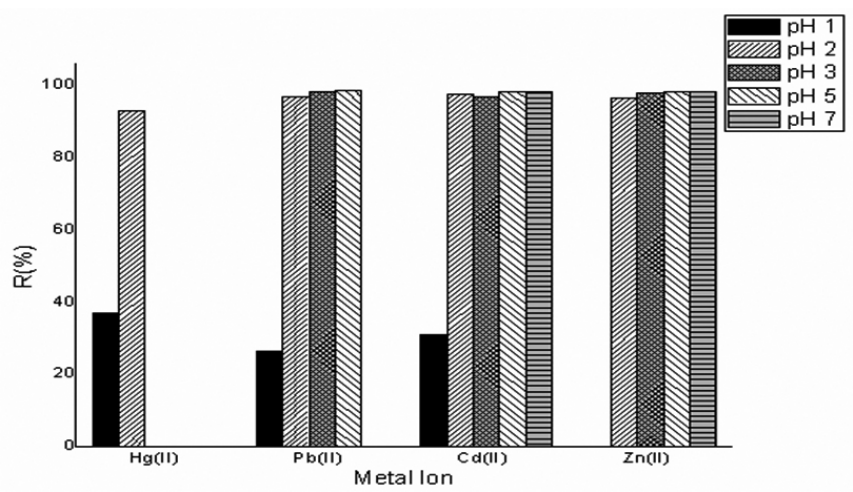

Fig. 9 Retention of metal ions at different $\mathrm{pHs}$ for P(APSA-co-AAc).

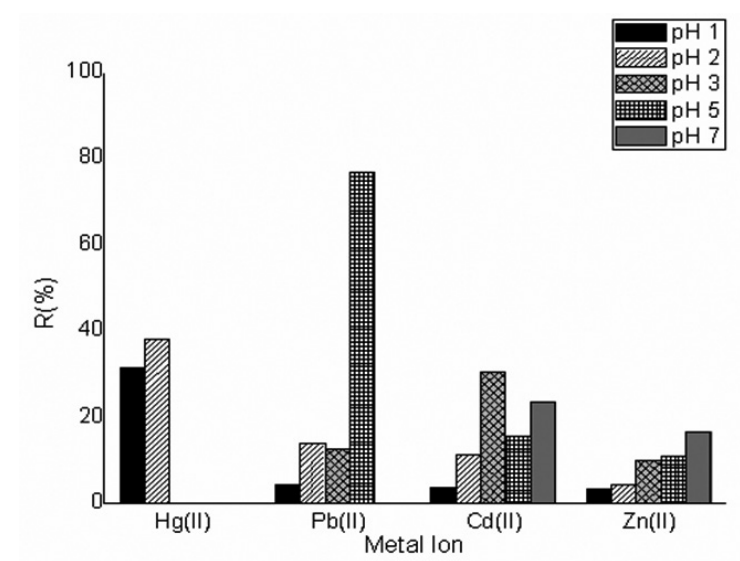
64.

Fig. 10 Retention results of metal ions at different $\mathrm{pHs}$ for Amberlite IRP-

Figures 8 and 9 show the optimum retention for $\mathrm{Hg}(\mathrm{II})$ was at a $\mathrm{pH}$ value of 2 for $\mathrm{P}(\mathrm{AAm}-\mathrm{co}$-ESS $)$ and $\mathrm{P}(\mathrm{APSA}-\mathrm{co}-\mathrm{AAc})$ resins. The optimum retention $\mathrm{pH}$ values for $\mathrm{Cd}(\mathrm{II})$ were $2-7$; for $\mathrm{Pb}(\mathrm{II}) 2-5$ (At $\mathrm{pH}>5$ it precipitates, therefore, it is not possible study at $\mathrm{pH} 7$ ), however, $\mathrm{Zn}$ (II) showed good retention capability in the $\mathrm{pH}$ range $2-7$, it is not retained at $\mathrm{pH} 1$.

Figure 10 shows the lower retention levels of all the metal ions studied using the commercial resin Amberlite IRP-64 in comparison to the synthesized $\mathrm{P}(\mathrm{AAm}-\mathrm{co}$-ESS) and P(APSA-co-AAc) resins. Different ion exchangers bearing the same groups can exhibit significantly different properties because the strengths of the groups depend on the nature of the supporting hydrocarbon structure. ${ }^{18}$ The higher retention of the synthesized resins in comparison with the commercial resin Amberlite IRP-64 can be explained due to the structure of the synthesized resins have low dissociation constant and interact more strongly with the metal ions, and the presence of two groups, the sulfonic and carboxylic acid groups on the synthesized resins available to interact with the metal ions and remove them. At higher $\mathrm{pH}$ the resins are deprotonated and the groups are free to exchange or complex the metal ion at low $\mathrm{pH}$. In addition, the commercial resin contains only a carboxylic acid group that is available to interact with the metal ions. Therefore, the active groups of the synthesized resins have better interactions with metal ions that the commercial resin Amberlite IRP-64.

Another reason for the better performance of the synthesized resins compared to the commercial one is that synthesized resins have higher swelling capacities than the commercial resin. Therefore, the active groups will be more accessible, and it will be easier for the metal ion in solution to diffuse into the synthesized resins.

\section{Effect of the contact time}

The interaction time between the metal ion and the active site of the resin, required to get an effective interaction may vary, being in some cases longer than that others.

Table 1. Retention of metal ions as a function of contact time with the resin

\begin{tabular}{|c|c|c|c|c|c|}
\hline & & & $\begin{array}{c}\text { Retention } \\
(\%)\end{array}$ & & \\
\hline Resin & Metal ion & $\mathbf{1 5}$ min & $\mathbf{3 0}$ min & $\mathbf{6 0}$ min & $\mathbf{1 2 0}$ min \\
\hline P(AAm-co-ESS) & $\mathrm{Pb}(\mathrm{II})$ a pH 5 & 99.4 & 99,4 & 99.4 & 99.4 \\
\hline P(APSA-co-AAc) & $\mathrm{Pb}(\mathrm{II})$ a pH 5 & 98.3 & 98.4 & 98.6 & 97.8 \\
\hline
\end{tabular}

Table 1 shows that the synthesized resins have fast retention kinetics. The $\mathrm{P}(\mathrm{AAm}-\mathrm{co}$-ESS) and $\mathrm{P}(\mathrm{APSA}-\mathrm{co}-\mathrm{AAc})$ resins reaches equilibrium before 15 min of contact with the metal ion solution. The P(APSA-co-AAc) shows a decrease at $120 \mathrm{~min}$, this decrease is not important considering the relative error $(0.34 \%)$ and according to the significance testing is due to random error and no systematic. ${ }^{26}$ The interaction of ion exchange groups with the metal ion is fast because the swelling of the resins is optimal for the diffusion of the metal ion into the pores of the resin, and the ion exchange groups have a high affinity for the metal ions in this study.

Maximum retention capacity

To achieve the adsorption capacity of the resins, its need to saturate it with consecutives cycles of charge with metal ion until reach the equilibrium, this is when the resin can't retain more metal ion.

Table 2 shows that the $\mathrm{P}(\mathrm{AAm}-\mathrm{co}$-ESS $)$ and $\mathrm{P}(\mathrm{APSA}-\mathrm{co}-\mathrm{AAc})$ resins were not saturated even after three consecutive cycles of being charged with metal ions and could continue to be charged with more metal ions at the optimal $\mathrm{pH}$ and contact time. This can be attributed to the high degree of swelling. These results suggest that P(AAGA-co-ESS) and P(AAGA-co-APSA) resins can be used in future applications of continuous process (column method).

Elution

The use of the resins in a continuously operated process, require that the resin's metal ion capacity should be maintained after the treatment with an eluent reagent, and the metal ion adsorbed by the resin should be easily released under appropriate conditions.

Regeneration

For the resin reusability, consecutives cycles of sorption-desorption were performed for both resins with the optimum eluent. This parameter corresponds to the number of times that the resin can be charged with the metal ion solution and then eluted without losing their retention capacity. For use in continued process for future application on industry, is necessary check if is possible to regenerate the resin in consecutives cycles of charge-discharge.

Figure 12 shows the regeneration of the synthesized resins, P(AAm-coESS) and P(APSA-co-AAc). The P(AAm-co-ESS) resin began to lose its retention capacity $(96.6 \%$ in the first cycle and $77.6 \%$ in the second cycle) and its elution proficiency (which decreases from $78.4 \%$ to $57.5 \%$ ) during consecutive cycles. However, its retention capacity increased during the third cycle to $95.5 \%$ and its elution increased to $66.3 \%$. It could be because not all the metal ions were removed in earlier cycles and because some amount of metal ions remained inside the pores of the resin.

P(APSA-co-AAc) began to lose its retention capacity $(96.0 \%$ in the first cycle and $92.5 \%$ in the second cycle) and its elution proficiency ( $78.6 \%$ in the first cycle and $65.2 \%$ in the second cycle) during consecutive cycles. However, in the third cycle, the retention continued to decrease to $91.0 \%$ (very close to $92 \%$ of the second cycle), but its elution increased to $70.5 \%$. 


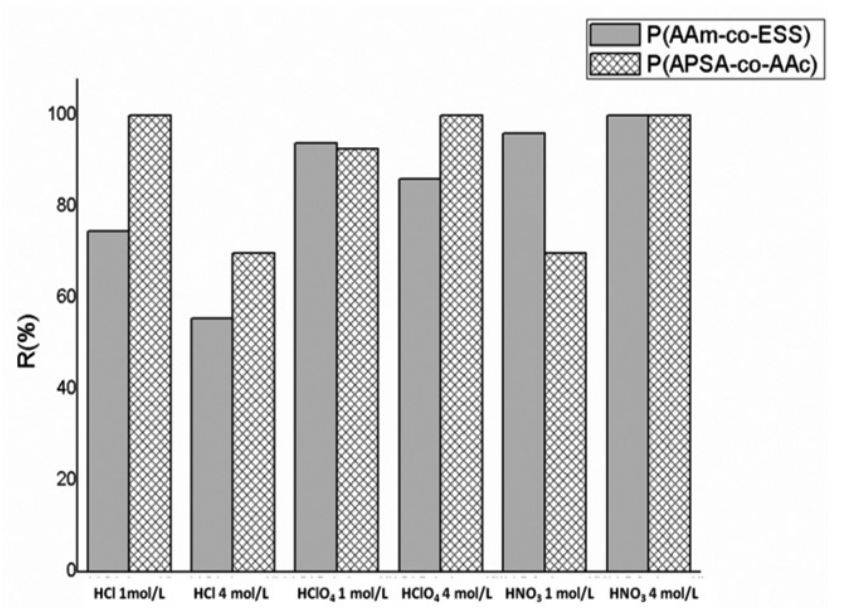

Fig. 11 Elution of $\mathrm{P}(\mathrm{AAm}-\mathrm{co}-\mathrm{ESS})$ and $\mathrm{P}(\mathrm{APSA}-\mathrm{co}-\mathrm{AAc})$ in contact with $\mathrm{Pb}(\mathrm{II})$.

Figure 11 shows better elution when using $4 \mathrm{~mol} / \mathrm{L} \mathrm{HClO}_{4}$, and 1 and $4 \mathrm{~mol} / \mathrm{L} \mathrm{HNO}_{3}$ for the $\mathrm{P}(\mathrm{AAm}-\mathrm{co}$-ESS) resin, and when using $1 \mathrm{~mol} / \mathrm{L} \mathrm{HCl}, 1$ and 4 $\mathrm{mol} / \mathrm{L} \mathrm{HClO}_{4}$, and $4 \mathrm{~mol} / \mathrm{L} \mathrm{HNO}_{3}$ for $\mathrm{P}(\mathrm{APSA}-\mathrm{co}-\mathrm{AAc})$. Both resins at maximum retention capacity with $\mathrm{Pb}(\mathrm{II})$ can be regenerated using these acids. For future industrial applications it is possible to regenerate both resins at their maximum retention capacities with $\mathrm{Pb}$ (II) using $\mathrm{HCl}_{1} \mathrm{HClO}_{4}$ or $\mathrm{HNO}_{3}$ acid.

Table 2. Results of maximum retention capacity of resins in contact with solution of $\mathrm{Pb}(\mathrm{II})$.

\begin{tabular}{|c|c|c|c|c|c|c|c|c|c|}
\hline \multirow{2}{*}{ Resin } & \multirow{2}{*}{$\begin{array}{l}\text { Metal } \\
\text { Ion }\end{array}$} & \multirow{2}{*}{ pH } & \multirow{2}{*}{ Cycle $N^{\circ}$} & \multirow{2}{*}{$\begin{array}{c}\text { Retanined mass } \\
(\mathrm{mg})\end{array}$} & \multirow{2}{*}{$\begin{array}{c}\text { mmols/g } \\
\text { resin }\end{array}$} & \multirow{2}{*}{$\begin{array}{l}\mathrm{mg} / \mathrm{g} \\
\text { resin }\end{array}$} & \multirow{2}{*}{ R (\%) } & \multirow{2}{*}{$\begin{array}{l}\text { Total mass } \\
\text { retained } \\
(\mathrm{mg})\end{array}$} & \multirow{2}{*}{$\begin{array}{c}\text { (MRC) } \\
\mathrm{mg} / \mathrm{g} \text { resin }\end{array}$} \\
\hline & & & & & & & & & \\
\hline \multirow[t]{3}{*}{ P(AAm-co-ESS) } & $\mathrm{Cd}(\mathrm{II})$ & 5 & 1 & 18.71 & 0.27 & 37.38 & 99.8 & 55.98 & 11.85 \\
\hline & $\mathrm{Cd}(\mathrm{II})$ & 5 & 2 & 18.66 & 0.27 & 37.28 & 99.5 & & \\
\hline & $\mathrm{Cd}(\mathrm{II})$ & 5 & 3 & 18.61 & 0.27 & 37.18 & 99.3 & & \\
\hline \multirow[t]{3}{*}{$\mathrm{P}(\mathrm{APSA}-c o-\mathrm{AAc})$} & $\mathrm{Pb}(\mathrm{II})$ & 5 & 1 & 18.27 & 0.26 & 36.57 & 97.5 & 55.04 & 110.17 \\
\hline & $\mathrm{Pb}(\mathrm{II})$ & 5 & 2 & 18.26 & 0.26 & 36.55 & 97.4 & & \\
\hline & $\mathrm{Pb}(\mathrm{II})$ & 5 & 3 & 18.51 & 0.27 & 37.05 & 98.7 & & \\
\hline
\end{tabular}

\section{Selectivity}

The selectivity indicates the preference of the material to one ion in comparison with another ion, i. e. the selectivity is a comparative value. It is a very important variable to know during the research on removal properties of a polymer or material. ${ }^{18}$ Inside a mixture of several metal ions, the interaction and preference of the resin could vary. To determine metal ion retention under competitive conditions, a test was performed.

Table 3. Ternary mixture selectivity for $\mathrm{P}(\mathrm{AAm}-\mathrm{co}-\mathrm{ESS})$ and $\mathrm{P}(\mathrm{APSA}-\mathrm{co}-\mathrm{AAc})$ at $\mathrm{pH} 5$.

\begin{tabular}{|c|c|c|c|c|}
\hline Resin & & $\mathrm{Cd}(\mathrm{II})$ & $\mathrm{Zn}(\mathrm{II})$ & $\mathrm{Pb}(\mathrm{II})$ \\
\hline & Feed (mg) & 1.3188 & 0.9311 & 2.9071 \\
\hline \multirow[t]{3}{*}{$\mathrm{P}(\mathrm{AAm}-\mathrm{co}$-ESS) } & Retention (mg) & 1.3144 & 0.9266 & 2.9041 \\
\hline & $\mathrm{R}(\%)$ & 99.7 & 99.5 & 99.9 \\
\hline & Feed (mg) & 1.3188 & 0.9311 & 2.9071 \\
\hline \multirow[t]{2}{*}{ P(APSA-co-AAc) } & Retention (mg) & 1.2897 & 0.9114 & 2.8515 \\
\hline & $\mathrm{R}(\%)$ & 97.8 & 97.9 & 98.1 \\
\hline
\end{tabular}

Table 4. Quaternary mixture selectivity for P(AAm-co-ESS) and P(APSA-co-AAc) at $\mathrm{pH} 2$.

\begin{tabular}{|c|c|c|c|c|c|}
\hline Resin & & $\mathbf{C d}(\mathbf{I I})$ & $\mathbf{Z n}(\mathbf{I I})$ & $\mathbf{P b}(\mathbf{I I})$ & $\mathbf{H g}$ (II) \\
\hline & Feed (mg) & 1.6157 & 1.0207 & 3.1337 & 4.0864 \\
\hline P(AAm-co-ESS) & Retention (mg) & 1.591 & 1.0056 & 3.1019 & 0.3025 \\
\hline & $\mathrm{R}(\%)$ & 98.5 & 98.5 & 98.9 & 93.1 \\
\hline P(APSA-co-AAc) & Feed (mg) & 1.6157 & 1.0207 & 3.1337 & 4.0864 \\
\hline & Retention (mg) & 1.5484 & 0.9793 & 3.0256 & 3.7825 \\
\hline & $\mathrm{R}(\%)$ & 95.9 & 95.9 & 96.6 & 92.6 \\
\hline
\end{tabular}


Tables 3 and 4 show a tertiary mixture of $\mathrm{Pb}(\mathrm{II})-\mathrm{Cd}(\mathrm{II})-\mathrm{Zn}$ (II) and a quaternary mixture of $\mathrm{Hg}(\mathrm{II})-\mathrm{Pb}(\mathrm{II})-\mathrm{Cd}(\mathrm{II})-\mathrm{Zn}$ (II) for $\mathrm{P}(\mathrm{AAm}-\mathrm{co}$-ESS) and $\mathrm{P}(\mathrm{APSA}-\mathrm{co}-\mathrm{AAc})$. The P(AAm- $\mathrm{co}$-ESS) and P(APSA-co-AAc) resins do not demonstrate metal ion selectivity, keeping a molar ratio of 20:1 (resin: metal ion) solution. The resins retain all metal ions with a very good retention at the specified optimal $\mathrm{pH}$. The synthesized resins in this study are efficient for these cations, and the removal is higher than $90 \%$ of every metal ion at low concentration.

\section{CONCLUSIONS}

The expected functional groups were observed in the infrared spectra, including a sulfonic acid peak for $\mathrm{P}(\mathrm{AAm}-\mathrm{co}$-ESS), and carboxylic acid and sulfonic acid peaks for P(APSA-co-AAc), all capable of exchanging or coordinating with metal ions. $\mathrm{P}(\mathrm{AAm}-\mathrm{co}$-ESS $)$ and $\mathrm{P}(\mathrm{APSA}-\mathrm{co}-\mathrm{AAc})$.

P(AAGA-co-ESS) and P(AAGA-co-APSA) resins demonstrated higher retention properties than the commercial resin, Amberlite IRP-64.

$\mathrm{P}(\mathrm{AAm}-\mathrm{co}$-ESS) showed a rapid interaction with the metal ion solution, in which equilibrium was reached before $15 \mathrm{~min}$. P(APSA-co-AAc) reached equilibrium at $60 \mathrm{~min}$.

The study of the maximum retention capacities showed that the resins were not saturated after three consecutive charging cycles, and they could continue being charged with more of the metal ion solution.

The best elution for P(AAm-co-ESS) was obtained with either $4 \mathrm{~mol} / \mathrm{L}$ $\mathrm{HClO}_{4}$ or 1 and $4 \mathrm{~mol} / \mathrm{L} \mathrm{HNO}_{3}$, and the best elution for P(APSA-co-AAc) was obtained with either $1 \mathrm{~mol} / \mathrm{L} \mathrm{HCl}, 1$ and $4 \mathrm{~mol} / \mathrm{L} \mathrm{HClO}_{4}$, or $4 \mathrm{~mol} / \mathrm{L} \mathrm{HNO}_{3}$.

$\mathrm{P}(\mathrm{AAm}-\mathrm{co}$-ESS) and P(APSA-co-AAc) were regenerated in consecutive charge-discharge cycles, but they lost their regeneration capacity during every charge-discharge cycle. P(AAm-co-ESS) in the third cycle improved the regeneration.

Finally, the $\mathrm{P}(\mathrm{AAm}-\mathrm{co}-\mathrm{ESS})$ and $\mathrm{P}(\mathrm{APSA}-\mathrm{co}-\mathrm{AAc})$ resins were not selective by using ternary and quaternary mixtures of $\mathrm{Hg}(\mathrm{II}), \mathrm{Cd}(\mathrm{II}), \mathrm{Pb}(\mathrm{II})$, and $\mathrm{Zn}(\mathrm{II})$, keeping the molar ratio $20: 1$ of resin: metal ion.

\section{ACKNOWLEDGMENTS}

The authors thank to FONDECYT (Grant No 1110079), PIA (Anillo ACT 130), and REDOC (MINEDUC Project UCO1202 at U. de Concepción).

\section{REFERENCES}

1. Acheampong, M., Meulepas, R., Lens Piet, N., J. Chem Tech Biotech, 85, 590 (2010).
2. Wielaw, W., Krzysztof, N., Sulkowska, A., Mikula, B., Wiersba, P., J. Appl. Polym. Sci., 128, 2611 (2013)

3. World Health Organization, Guidelines for drinking-water Quality, Volume 1 recommendations, 2006

4. Rivas, B.L., Ovando P., Villegas S. J. Appl. Polym. Sci., 83, 2595-2599 (2002).

5. Rivas, B.L., Pooley S.A., Aceiton E. J. Appl. Polym. Sci., 84, 1251-1256 (2002).

6. Rivas, B L., Villegas S, Ruf B., J. Appl. Polym. Sci., 99, 3266-3274 (2006).

7. Rivas, B.L., Quilodrán B, Quiroz E., J. Appl. Polym. Sci., 99, 697-705 (2006).

8. Rivas, B.L., Castro A., J. Appl. Polym. Sci., 90, 700- 705 (2003).

9. Rivas, B.L., Villegas V. J. Appl. Polym. Sci., 98, 525-530 (2005).

10. Rivas, B.L., Pereira, E., Cid, R., Geckeler, K.E. J. Appl. Polym. Sci., 95, 1091-1099 (2005)

11. Vinodh, R., Padmavathi, R., Sangeetha, D. Desalination, 267, 267-276 (2011).

12. Rivas, B.L., Villegas S., Ruf B., Peric I. J. Chil. Chem, Soc., 52, 11641168 (2007).

13. Gao, B., Gao, X., Lei, Q. J. Macromol. Sci. Part A, 48, 119-127 (2011).

14. Rivas, B.L., Muñoz C. J. Appl. Polym. Sci., 114, 1587-1592 (2009).

15. Wolowicz, A., Hubicki, Z., Solvent Ext. Ion Exchange, 28, 124-129 (2010).

16. Abdel-Aziz, H.M., Hanafi, H.M., Abozahra, S.F., Siyam, T. Int. J. Polym. Mat., 60, 89-101 (2011).

17. Ulf W. Gedde, Polymer Physics, Chapman and Hall, London, 1995.

18. Soldatov V.S, Zelenkowski, V.M., Orlovskaya, L.A. React. Funct. Polym., 71, 49-61 (2011).

19. Andrei A. Zagorodni, Ion Exchange Materials, Properties and Applications, Elsevier, great Britain, 2007.

20. C. E. Harland, Ion Exchange: Theory and practice, Royal Society of Chemistry Paperbacks, Letchworth, 1994.

21. Sánchez, J., Toledo, L., Rivas, B.L., Muñoz, E., J. Chil. Chem. Soc. 58, 1986-1993 (2013)

22. Moreno-Villoslada, I., Rivas, B.L., J. Phys. Chem. B, 106, 9708-9711 (2002).

23. Seguel, G.V., Rivas, B.L., Polyhedron, 18, 2511-2518 (1999).

24. Rivas, B.L., Pereira, E., Cid, R., Geckeler, K.E., J. Appl. Polym. Sci., 95, 1091-1099 (2005).

25. Rivas, B.L., Pooley, S.A., Luna, M., Macromol. Rapid Commun. 21, $905-$ 908 (2000).

26. James N. Miller, Jane C. Miller, Statistic and Chemometrics for Analitical Chemestry, Prentice Hall, Spain, 2000. 